JURNAL TEKKNOSAINS

VOLUME 4

No. 1, 22 Desember 2014

Halaman 1-102

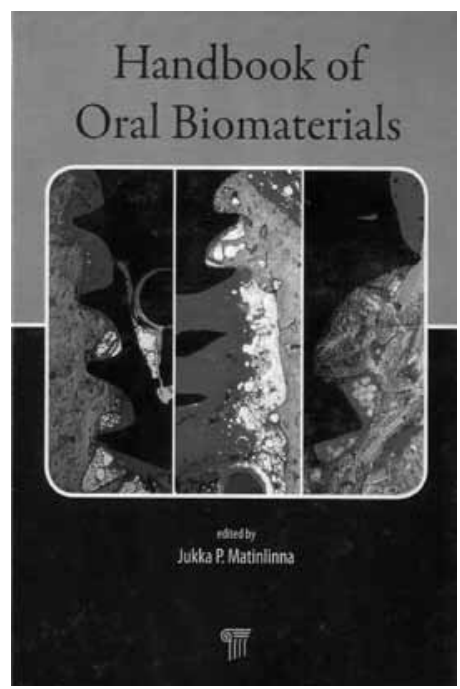

Judul Buku

Editor

Penerbit

Tahun

Tebal

\section{RESENSI \\ BIOMATERIAL UNTUK RESTORASI FUNGSI DAN ESTETIKA}

\author{
H. Dedy Kusuma Yulianto \\ Fakultas Kedokteran Gigi \\ Universitas Gadjah Mada
}

: Handbook of Oral Biomaterials

: Jukka P. Matinlinna

: Pan Stanford Publishing, Singapore

: 2014

: 649 halaman

\section{PENGANTAR}

Tidak dapat dipungkiri bahwa perkembangan teknologi dalam bidang biomaterial memberi kontribusi besar dalam dunia kedokteran gigi. Keterlibatan disiplin ilmu lain dalam mengembangkan teknologi yang relevan memberi kontribusi yang sangat besar dalam lahirnya inovasi baru baik dari segi teknik maupun filosofi perawatan dental.Tujuan utama adalah peningkatan kualitas kesehatan yang berkorelasi positif dengan kualitas kehidupan baik dalam aspek individu maupun sosial.

\section{PEMBAHASAN}

\section{Biomaterial (Fungsi dan Aplikasi)}

Handbook of Oral Biomaterials dengan total 649 halaman, mempunyai konstruksi yang sistematis dan terstruktur antarsatu bab dengan bab berikutnya. Model penyajian tiap bab menggunakan pendekatan perpaduan antara konsep dan teori, memudahkan pembaca untuk bisa memahami konten yang disajikan di dalam 19 bab. Alur yang tersusun rapi dalam menguraikan suatu teori memberikan kemudahan bagi pembaca untuk dapat mengikuti alur secara skematis. Bab 1 dimulai dengan topik mengenai bahan bonding, yang merupakan starting point sebuah mata rantai restorasi fungsi dan estetika. Pemahaman mekanisme bonding kemudian diperkaya di bab 2 yang membahas mengeani prinsip dasar proses mineralisasi dan demineralisasi jaringan keras gigi (email dan dentin). Proses mineralisasi primer dan sekunder jaringan keras gigi merupakan proses yang kompleks dengan keterlibatan faktor fisik, kimiawi, dan biologi. Informasi perkembangan terkini bahan primer dan bahan pengikat (couplingagent) yang berperan penting dalam proses restorasi diuraikan di dua bab, yaitu bab 1 dan 11, memberi pengetahuan kepada pembaca mengenai mekanisme kimiwai terjadinya ikatan antara komponen organic dan inorganic material restorasi. Biological activity sebagai dasar reaksi biologis yang terjadi dalam jaringan hidup terdapat di bab 9. Bab 9 mempunyai korelasi dari sisi konsep dan aplikasi klinis dengan prinsip biokompatibilitas 
yang disajikan di dalam bab 5. Kedua sifat tersebut menjadi faktor kunci keberhasilan restorasi.Proses dalam restorasi fungsi dan estetika yang dimulai dari pemahaman dasar mngenai proses bonding berujung pada pengetahuan mengenai material restorasi yang dapat diaplikasikan secara langsung (direct restoration) maupun tidak langsung (indirect restoration). Jenis, fungsi dan kegunaan masing-masing material restorasi seperti logam, polymer, wax, akrilik, dan material lainnya diuraikan di dalam bab 3 dan 6. Titanium sebagai material pilihan dalam teknik implant dibahas di bab 9,10,13, sedangkan keramik khususnya zirconia dan alumina dapat ditemukan di bab 3, 14-16.

Poin penting lainnya dalam mata rantai proses restorasi fungsi dan estetika adalah prinsip dasar mengenai surface treatment dan conditioning yang dapat dipelajari di bab 11. Aplikasi teknologi surface treatment dalam bidang material implant gigi dapatmemodifikasi sifat permukaan material implant disesuaikan dengan spesifikasi kegunaan serta reaksi yang diharapkan terjadi dengan jaringan biologis (host). Sebagai contoh pelapisan permukaan implant berbasis material titanium dengan material yang bersifat osteocunductive dan osteopromotif dapat memicu perlekatan yang baik antara implantdengan struktur tulang.Beban yang diterima oleh artificial organ.

Prognosis keberhasilan restorasi juga dipengaruhi oleh kemampuan material beradaptasi dengan lingkungan oral di sekitarnya.Bebanoklusi,stresfisikmerupakan salah satu contoh faktor biomekanika yang menentukan prognosis tersebut. Prinsip biomekanika sebagai aspek fundamental dalam mengakulasi kemampuan material dari sisi mekanis dan dan fisik diulas di bab 3 dan 4 . Restorasi yang over atau under kontur pada permukaan gigi memberikan beban berlebih pada jaringan periodontal. Apabila terjadi dalam rentang waktu yang panjang, maka akan menimbulkan reaksi patologis yang tidak menguntungkan bagi jaringan periodontal serta jaringan di sekitarnya. Respon biologis dengan jaringan periodontal dapat dipelajari lebih mendalam di di bab 19.

Bioaktif material sebagai tonggak baru perkembangan material dari material generasi pertama menuju ke generasi kedua dan ketiga dijelaskan di dalam bab 12. Terakhir, informasi mengenai dental informatics dan digital dentistry dimuat di bab 18. Kedua bidang tersebut (dental informatics dan digital dentistry) termasuk hal baru yang saat ini sedang berkembang pesat dan sangat menarik untuk dipelajari. Perkembangan teknologi informasi dan komunikasi memberi kontribusi besar dalam perkembangan kedua bidang tersebut.

\section{Biomaterial (Perspektif dan Relevansi Klinis)}

Secara umum dokter gigi akan melakukan prosedur restorasi terhadap gigi dan jaringan sekitarnya yang mengalami kerusakan akibat trauma atau penyakit. Prosedur restorasi tersebut menggunakan material dental untuk mengembalikan fungsi baik secara kegunaan maupun estetika. Sebagai contoh, gigi yang mengalami karies akan mengalami kerusakan struktur jaringan kerasnya bahkan sampai ke jaringan lunak (pulpa dan jaringan periodontal) apabila terjadi penyebaran infeksi.Untuk mengembalikan fungsi gigi tersebut seperti ketika sebelum terserang penyakit, maka dibutuhkan material dental berupa material restorasi (resin komposit, semen glass ionomer, amalgam, mahkota jaket porselein, dan lain-lain).

Selain material restorasi dikenal juga material bioaktif (bioactive material), yaitu material yang mampu menstimulasi respon biologis spesifik pada titik kontak (interface) antara permukaan material dengan jaringan hidup dan atau cairan tubuh.Rekonstruksi dan perbaikan jaringan yang mengalami kerusakan atau kehilangan sebagian strukturnya telah melibatkan berbagai disiplin ilmu, seperti bidang teknik, farmasi, kimia, 
biologi, ilmu material, fisika, matematika, sehingga melahirkan terminologi baru yaitu bioengineering. Jenis material yang digunakan untuk tujuan tersebut didefinisikan sebagai biomaterial. Tahun 1960, Professor Hench memperkenalkan kepada dunia mengenai penemuan terbaru material bioaktif merupakan tonggak awal peralihan teknologi material dari material generasi pertama (material prosthesis/artificial digunakan untuk menggantikan jaringan yang hilang/rusak) menuju ke material generasi kedua yang mampu berikatan secara kimiawi dengan jaringan biologis. Perkembangan teknologi dan riset mengenai material bioaktif terus mengalami kemajuan sejak tahun 1967 sampai tahun 2009 dengan ditandai mulai komersialisasi prototype 45S5-Bioglass yang mempunyai struktur kimiawi $\mathrm{SiO}_{2}-\mathrm{Na}_{2} \mathrm{O}-\mathrm{CaO}-\mathrm{P}_{2} \mathrm{O}_{5}$ menjadi beberapa produk biomedis yang dapat diaplikasikan sebagai material regenerasi maupun material stimulasi pembentukan/ regenerasi jaringan. Perkembangan dunia biomaterial berlangsung secara pararel dengan perkembangan teknologi yang relevan, sehingga memberi banyak peluang serta wacana baru kepada klinisi maupun peneliti untuk mengembangkan material generasi ketiga (genetic dan biomolecullar design). Di dalam bab 8 Leena Hupa dan Susanne Fagerlund memprediksi bahwa sampai dengan tahun 2020 dinamika riset desain molekuler sebagai perancah (scaffold) untuk melakukan rekayasa terhadap jaringan hidup mengarah ke material generasi ketiga. "NovaBone" dan "NovaMin" merupakan contoh komersialisasi dari prototype $45 \mathrm{S5}$ Bioglass yang sudah mendapatkan approval oleh FDA (US Food and Drug Administration). Teknologi NovaMin diaplikan sebagai material anti hipersensitif dengan target organ utama adalah jaringan dentin.

Hipersensitif dentin merupakan suatu kondisi dimana pasien akan mengalami rasa nyeri yang tajam apabila satu atau beberapa gigi dalam rongga mulut terekspos oleh stimulus (makanan/minuman panas, dingan, manis, asam) yang dapat menginisasi terjadi perubahan suhu secara mendadak di sekitar jaringan gigi. Ditengarai adanya permukaan dentin yang tidak terlindungi oleh email menjadi media yang mengonduksikan stimulus menuju pusat persepsi nyeri. Mekanisme pelepasan partikel glass yg terdapat di dalam NovaMin terjadi dengan menggunakan sistem controlled release dan persipitasi ion pada permukaan dentin. Reaksi tersebut akan memicu peningkatan $\mathrm{pH}$ di sekitar jaringan dan kemudian terjadi presipitasi Hydroxyapatite (HAP) untuk menutup pori-pori dentin yang dikenal dengan tubuli dentin. Penutupan tubuli dentin ini diharapkan dapat menciptakan barier terhadap ekspos stimulus pada permukaan dentin. Riset dalam bidang ini sangat terbuka luas karena sampai saat ini belum ada material yang mampu menutup tubuli dentinalis secara permanen.

Pengetahuan mengenai material dental dan biomaterial disajikan secara komprehensif dalam buku ini. Penyajian yang dikemas secara ringkas, terstruktur dan terintegrasi atar satu bab dengan bab yang berikutnya menjadikan buku ini sangat bermanfaat sebagai referensi bagi klinisi untuk selalu mengikuti perkembangan teknologi material terbaru. Seorang klinisi yang handal akan memadukan keahlian motorik yang ditunjang dengan penguasaan ilmu material yang baik. Hal tersebut menjadi penting mengingat bahwa teknik restorasi gigi selalu berkembang dinamis seiring dengan perkembangan teknologi.Sebagai contoh adalah material resin komposit yang diulas dalam bab 3. Material restorasi berbasis resin komposit mulai diperkenalkan pada tahun 1950 yang ditandai dengan penggunaan material glass-filled PMMA. Tahun 1960 PMMA mulai ditinggalkan dan dan sebagai gantinya material organic bisGMA mulai popular digunakan sebagai matrik sampai dengan sekarang. Selain aspek fungsional, faktor estetika dipandang 
berperan vital untuk mengakomodasi perubahan gaya hidup masyarakat modern. Teknologi nanopartikel yang diadopsi untuk membuat filler berukuran nano sebagai bahan pengisi matrik di dalam material berbasis resin komposit menjawab tantangan tersebut. Sifat superior dari nanopartikel baik secara mekanis maupun estetis memberikanperspektif baru dalam teknik restorasi.

Aplikasi material restorasi untuk melakukan perawatan yang optimal perlu didukung pengetahuan mengenai karakteristik spesifik yang berbeda antartiap jenis material. Sebagai contoh teknik aplikasi bahan bonding. Bahan bonding dalam teknik restorasi mempunyai peran vital karena restorasi yang baik mensyaratkan adanya bonding atau ikatan yang bagus antara material restorasi dengan permukaan jaringan keras gigi. Teknik aplikasi bahan bonding sangat sensitif karena terkait dengan struktur dan sifat kimiawi penyusun bahan bonding. Di dalam bab 1, pembaca bisa mendapatkan informasi yang sangat detail mengenai perbedaan tiap jenis bahan bonding serta bagaimana cara aplikasi yang ideal untuk tiap jenis bahan bonding tersebut. Penjelasan mengenai perbedaan mekanisme interaksi molekuler antara berbagai jenis functional monomer yang terdapat di dalam bahan bonding dengan hydroxyapatite (HAp) diuraikan secara detail.

Bahan bonding secara garis besar dikelompokkan ke dalam 2 kelompok yaitu: Etch $\mathcal{E}$ Rinse Adhesive atau disingkat EERAs dan Self-Etch Adhesive (SEAs). Fungsi bahan bonding adalah sebagai bahan pengikat antara material restorasi dengan jaringan keras gigi (email dan dentin). Ikatan ini diperlukan agar material restorasi dapat berfungsi secara optimal sebagai material substitusi/artificial yang diharapkan mempunyai kemiripan secara sifat, struktur, serta karakteristrik yang dimilikinya dengan jaringan keras gigi. Email mempunyai komponen penyusun anorganik dengan persentase yang lebih tinggi dibanding dentin. Perbedaan komposisi ini tentu saja mempunyai implikasi pada perbedaan jenis ikatan atau interaksi antar-partikelpartikel yang terkandung di dalam email dengan bahan bonding. Tantangan terbesar adalah bagaimana mendapatkan efektivitas perlekatan yang equal antara bahan bonding dengan jaringan keras gigi yang mempunyai perbedaan struktur kimiawi dan biologi. Bonding ke permukaan email dengan kandungan komponen inorganic sebesar 99\% lebih predictable untuk dicapai bila dibandingan dengan bonding ke permukaan dentin yang mempunyai komponen inorganic lebih sedikit persentasenya. Untuk menjawab tantangan tersebut pemahaman mengenai konsep biomineralisasi dan biodemineralisasi jaringan keras menjadi sangat fundamental. Penggunaan bahan etsa asam phosphoric acid pada teknik Etch $\mathcal{E}$ Rinse Adhesive (EERAs) akan memberikan kekuatan yang optimal apabila diaplikasikan pada permukaan email, karena proses etsa asam pada permukaan email akan membentuk micropit, hasil dari proses demineralisasi prisma email. Micropit ini akan memberikan retensi yang maksimum. Berbeda apabila bahan etsa asam diaplikasikan pada dentin. Retensi maksimum tidak akan terjadi karena bahan etsa asam akan menyebabkan terjadinya demineralisasi komponen anorganik dentin yang masif, sehingga kolagen akan terekspos, dan kemudian akan membentuk ikatan antara partikel dalam bahan bonding dengan permukaan dentin yang terekspos, dikenal dengan hybrid layer. Akibat kerusakan masif komponen anorganic dentin berakibat hybrid layer yang terbentuk relative tebal dan tidak homogen.Disinilah letak area kritis terhadap retensi yang dihasilkan. Hybrid layer yang tebal dan tidak homogen akan mudah terjadi proses degradasi akibat reaksi hydrolysis dan aktivitas enzymatic matrix metalloproteinase (MMP). Permukaan dentin lebih bersahabat dengan teknik SEAs dibandingkan dengan EERAs, karena teknik SEAs mempunyai $\mathrm{pH}$ 
yang tidak terlalu tinggi ( $\mathrm{pH} 2-2,4)$ sehingga proses demineralisasi komponen anorganik dentin tidak se-masif yang terjadi pada teknik EERAs. Keuntungan yang diraih dari teknik SEAs, partikel dalam bahan bonding akan membentuk ikatan dengan kolagen lebih homogen dengan ketebalan yang ideal, sehingga lebih resisten terhadap proses degradasi akibat reaksi hydrolysis dan aktivitas enzymatic. Pertanyaan yang timbul kemudian adalah bagaimana mendapatkan retensi yang equal pada permukaan jaringan keras (email dan dentin). Pertanyaan ini memberi inspirasi dan peluang untuk terus mengembangkan bahan bonding yang bisa diaplikasikan baik pada permukaan email maupun dentin dengan kualitas retensi yang equal. Sampai saat ini rekomendasi yang disarankan seperti yang diuraikan di dalam buku ini adalah dengan melakukan kombinasi antara dua teknik EERAs dengan
SEAs pada permukaan email dan dentin. Sehingga kekurangan dari masing-masing teknik bisa diantisipasi. Argumentasiscientific dari rekomendasi yang ditawarkan tersebut secara jelas diuraikan di bab 1 .

\section{SIMPULAN}

Buku ini sangat bermanfaat bagi para klinisi, peneliti atau yang mendalami dan mempunyai minat dalam bidang biomaterial. Perkembangan ilmu material dental dan biomaterial yang begitu pesat merupakan tantangan sekaligus peluang untuk melakukan inovasi serta terobosan baru baik dari sisi teknik aplikasi material maupun fungsi dari material tersebut. Harapan ke depan bahwa semakin banyaknya riset dalam bidang ini akanbersinergi secara positif dengan harapan masyarakat untuk mendapatkan pelayanan kesehatan yang semakin baik serta peningkatan kualitas hidup manusia di masa datang. 